\title{
CARACTERIZAÇÃO MORFOLÓGICA DE SEMENTES, PLÂNTULAS E DA GERMINAÇÃO DE Dimorphandra wilsonii Rizz. - FAVEIRO-DE-WILSON (FABACEAE- CAESALPINIOIDEAE) ${ }^{1}$
}

\author{
JOSÉ CARLOS LOPES ${ }^{2}$, MIELE TALLON MATHEUS ${ }^{3}$
}

\begin{abstract}
RESUMO - Objetivou-se estudar a morfologia de sementes e plântulas de Dimorphandra wilsonii Rizz. caracterizando-se as sementes interna e externamente e os processos de desenvolvimento e de diferenciação dos estádios das plântulas. Foram também determinados a curva de embebição das sementes, o peso de mil sementes e o número de sementes por quilograma. Um quilograma de sementes possui, em média, 2.560 unidades. Estas apresentam tecido de reserva, no qual o tégmen está fortemente aderido e os tegumentos são duros e impermeáveis à água. A morfologia de sementes e plântulas fornece subsídios que facilitam o reconhecimento da espécie.
\end{abstract}

Termos para indexação: morfologia, sementes duras, propagação de plantas.

\author{
MORPHOLOGICAL CHARACTERIZATION OF SEEDS, SEEDLINGS AND GERMINATION \\ OF Dimorphandra wilsonii Rizz. - FAVEIRO-DE-WILSON (FABACEAE-CAESALPINIOIDEAE)
}

\begin{abstract}
The objective was to study the morphology of the seeds and seedlings of Dimorphandra wilsonii Rizz. characterizing the seeds internally and externally, as well as describing the processes of development and differentiation of the seedlings phases. The soaking curve, the thousand-seed weight and the number of seeds per kilogram were also determined. One kilogram of the seeds corresponded to a number of 2.560 seeds in average. The seeds have endosperm, in which the tegmen is strongly attached and the teguments are hard and impermeable to water. The seed and seedling morphology gives informations that facilitates the recognition of this species.
\end{abstract}

Index terms: morphology, hard seeds, plants propagation.

\section{INTRODUÇÃO}

O faveiro-de-wilson (Dimorphandra wilsonii Rizz.) é uma leguminosa arbórea, encontrada na região de Paraopeba, no Estado de Minas Gerais (Silva, 1986), que possui boas propriedadesmedicinais, pois apresentaemseus frutos potencial para extração de glicosídeos flavonóides, especialmente a rutina (Fernandes et al., 2007). Entretanto, é considerada, na Lista Vermelha das Espécies Ameaçadas de Extinção da Flora de Minas Gerais, como vulnerável à extinção (Mendonça e

Submetido em 30/05/2007. Aceito para publicação em 18/11/2007.

${ }^{2}$ Engenheiro Agrônomo, Dr., Prof. Associado, Departamento de Produção Vegetal, Centro de Ciências Agrárias (CCA) - UFES - Campus de Alegre, Cx. Postal 16, CEP 29500-000,Alegre-ES, jclopes@cca.ufes.br; jcufes@bol.com.br
Lins, 2000). Desde a época de sua descrição, em 1969, $D$. wilsonii é considerada uma espécie rara, havendo, atualmente, registros de que o número total de adultos remanescentes, na natureza, seja de apenas 11 indivíduos, todos na região de Paraopeba (Fernandes et al., 2007).

Estudos que visam o conhecimento da morfologia de frutos, sementes e plântulas de espécies arbóreas são ainda escassos na literatura referencial, tendo como exemplos os trabalhos de Ferreira et al. (1998) com Dipteryx alata Vogel; Cruz e Carvalho (2003) com Micropholis venulosa Mart. \&

${ }^{3}$ Engenheiro Florestal, aluno do Programa de Pós-graduação em Produção Vegetal, bolsista CAPES, CCA-UFES, Cx. Postal 16, CEP 29500-000, Alegre-ES, miele.tallon@bol.com.br 
Eichler; Silva et al. (2003) com Bauhinia forficata Linn.; Melo et al. (2004) com Hymenaea intermedia var. adenotricha (Ducke) Lu \& Lang.; Abreu et al. (2005a) com Allophylus edulis (St.-Hil.) Radlk; Silva e Matos (1991) com Erythrina velutina Willd. e Abreu et al. (2005b) com Drimys brasiliensis Miers. Estudos envolvendo a morfologia de sementes podem auxiliar no entendimento do processo de germinação, vigor, armazenamento, viabilidade e métodos de propagação das espécies. Além disso, a caracterização morfológica de sementes fornece subsídios para diferenciar espécies e caracterizar aspectos ecológicos da planta, como a dispersão, estabelecimento de plântulas e fase da sucessão ecológica. Para Piña-Rodrigues et al. (1990) o potencial de estabelecimento de uma população em um habitat é essencialmente controlado pelo fluxo de propágulos. Entretanto, sabe-se que o tamanho dos frutos e sementes, além de outras formas de atração, como cheiro e coloração, são um dos fatores que podem influenciar na dispersão dos propágulos, uma vez que, conforme tais autores, o tamanho do fruto e da semente está diretamente relacionado com a quantidade de reservas armazenadas nos tecidos e sua atratibilidade e funcionalidade em relação aos agentes dispersores.

Durante o processo de germinação da semente, o início do desenvolvimento da plântula é marcado pela protrusão da radícula (Souza, 2003). Os trabalhos sobre morfologia de plântulas têm merecido atenção há algum tempo, quer sejam como parte de estudos morfo-anatômicos, objetivando ampliar o conhecimento sobre determinada espécie ou grupamento sistemático de plantas, quer visando o reconhecimento e identificação de plântulas de certa região, dentro de um enfoque ecológico (Oliveira, 1993). Segundo o mesmo autor, o conhecimento morfológico da plântula permite caracterizar famílias, gêneros e até mesmo espécies e tem sido aplicado no inventário florestal de muitas regiões de clima temperado e tropical.

Levando-se em consideração o número reduzido de pesquisas com espécies nativas do cerrado brasileiro, objetivou-se com este trabalho estudar a morfologia externa e interna de sementes e a morfologia das plântulas de Dimorphandra wilsonii Rizz.

\section{MATERIAL E MÉTODOS}

Coleta das sementes. As sementes de Dimorphandra wilsonii foram coletadas em matrizes existentes no município de Paraopeba, estado de Minas Gerais, em setembro de 2004 e conduzidas para o Jardim Botânico da Fundação ZôoBotânica de Belo Horizonte (FZB-BH), onde permaneceram armazenadas em sacos de papel, em condições naturais de ambiente, pelo período de cinco meses. Posteriormente, em sacos de polietileno, essas embalagens foram levadas para o Laboratório de Análise de Sementes do Centro de Ciências Agrárias da Universidade Federal do Espírito Santo (CCAUFES), em Alegre-ES, para condução dos estudos.

Imediatamente após o recebimento das sementes, foi avaliado o teor de água inicial das sementes, pelo método de estufa a $105 \pm 3^{\circ} \mathrm{C}$ por 24 horas (Brasil, 1992).

Caracterização morfológica da semente. No estudo das características externas, foram utilizados 20 exemplares bem desenvolvidos para as avaliações. Foram descritas as características morfológicas, como comprimento, largura e espessura, com auxílio de um paquímetro com precisão de $0,1 \mathrm{~mm}$. O comprimento foi medido da base até o ápice e a largura e espessura foram medidas na linha mediana das sementes.

Para a caracterização interna das sementes, utilizaramse 20 sementes. Estas foram escarificadas com lixa d'água $\mathrm{n}^{\mathrm{o}} 100$, do lado oposto ao hilo, imersas em água destilada por 24 horas e fervidas por 20 minutos para amolecimento dos tegumentos. As seções longitudinais e transversais foram feitas, exatamente, na porção mediana das sementes (Groth e Liberal, 1988), utilizando-se bisturi, visando-se à adequada observação do embrião, sendo as descrições feitas com auxilio de um microscópio estereoscópico.

Caracterização de plântulas e da germinação. A caracterização da germinação e a descrição morfológica das plântulas foram feitas semeando-se 20 sementes em caixa "gerbox" contendo vermiculita como substrato, umedecida com água destilada até atingir $60 \%$ da capacidade de retenção de água, calculado de acordo com Brasil (1992). As sementes foram mantidas em germinador com temperatura alternada de $20-30^{\circ} \mathrm{C}$ e fotoperíodo 8-16 horas luz/escuro. Devido ao comportamento das sementes, observadoatravésda curvadeembebição, quandoestasmostraram possuir tegumento duro, as mesmas foram escarificadas com lixa d'água $\mathrm{n}^{\circ} 100$, do lado oposto ao hilo, antes de serem colocadas para germinar. As sementes germinadas foram selecionadas e as plântulas transferidas para copos individuais contendo água destilada, sendo o suporte das mesmas feito através de uma folha de isopor acoplada à boca dos copos, para descrição das fases de germinação. Seguindo-se a metodologia utilizada por Silva e Matos (1991) com sementes de Erythrina velutina, foram descritos os processos de desenvolvimento e de diferenciação dos estádios, por meio de observações diárias, para descrição morfológica das plântulas. A primeira fase foi caracterizada pelo intumescimento da semente até o aparecimento da raiz primária. Na segunda fase, foi considerada a emissão dos cotilédones, sem a formação dos protófilos. Na terceira, os protófilos formados caracterizaram a plântula normal. 
Peso de mil sementes e número de sementes por quilograma. Os testes físicos foram feitos segundo as recomendações das Regras para Análise de Sementes, utilizando-se oito repetições de 100 sementes (Brasil, 1992).

\section{RESULTADOS E DISCUSSÃO}

$\mathrm{O}$ uso de alguns termos referentes à análise morfológica das sementes e plântulas foi baseado em Groth e Liberal (1988); Barroso et al. (1999); Souza (2003) e Vidal e Vidal (2003).

As características físicas das sementes encontram-se na Tabela 1. A Figura 1 mostra a curva de embebição de água pelas sementes, constatando-se a existência de tegumentos duros e impermeáveis à água nas sementes desta espécie. Conforme a Figura 2A, Dimorphandra wilsonii apresenta semente madura de elíptica a reniforme, oblonga e algumas vezes levemente recurvada; com comprimento médio de $17,9 \mathrm{~mm}$ (variando de 16,0-19,0mm); largura média de $6,7 \mathrm{~mm}(6,0-7,0 \mathrm{~mm})$ e espessura média de 4,3mm (3,0- 5,0mm). As medidas das sementes estão em acordo com os intervalos apresentados por Alves et al. (2004). A massa fresca de uma semente, em média, é 380mg e a massa seca de $340 \mathrm{mg}$. A semente é bitegumentada, com tégmen fortemente aderido ao albúmen, testa córnea com superfície lisa e brilhante, de coloração marrom-clara a avermelhada e tégmen membranáceo e amarelo-ocre; hilo elipsóide, homócromo, de tamanho muito reduzido, localizado na base da semente, com maior comprimento no sentido transversal ao maior eixo da semente; micrópila inconspícua; rafe apresentando-se inicialmente como uma depressão ao lado do hilo e posteriormente como cicatriz no dorso da semente, da base ao ápice; a calaza visível como uma faixa mais escura do que a testa e circunda a semente. Embrião axial, invaginado, com dois cotilédones foliáceos, adnatos, opostos e iguais, elíptico-oblongos, lisos, membranáceos,

TABELA 1. Características físicas da semente de Dimorphandra wilsonii Rizz. Laboratório de sementes, CCA - UFES. Alegre-ES, 2007

\begin{tabular}{lc}
\hline \multicolumn{1}{c}{ Características } & Valores \\
\hline Umidade (\%) & 8,00 \\
Peso de mil sementes $(\mathrm{g})$ & 391 \\
Número de sementes/kg & 2.560 \\
Comprimento (mm) & $17,9 \pm 0,99$ \\
Largura (mm) & $6,7 \pm 0,48$ \\
Espessura $(\mathrm{mm})$ & $4,3 \pm 0,67$ \\
\hline
\end{tabular}

de coloração amarelada, com bordo inteiro que se invagina na base, no ponto de inserção do eixo hipocótilo-radícula (Figura 2B), apresentando cada um, em média, 1,60cm de comprimento por $0,60 \mathrm{~cm}$ de largura. Eixo hipocótilo-radícula curto, reto e cilíndrico, de coloração amarelo-esbranquiçada. Plúmula conspícua, com dimensões bem reduzidas. O tecido de reserva de transparente a esbranquiçado, de carnoso a gelatinoso quando a semente está hidratada e córneo quando não hidratada, envolve os cotilédones (Figura 2C). Como não foi feito o estudo de ontogenia das sementes, segue-se a sugestão de Aqüila (2004) e denomina-se o tecido de reserva como albúmen.

As características morfológicas das sementes de Dimorphandra wilsonii se aproximam das verificadas por Ferreira et al. (2001) em Dimorphandra mollis Benth., o que pode servir como um indicativo positivo para a utilização das características morfológicas de sementes na identificação sistemática deste gênero.

A germinação foi caracterizada como epígea e fanerocotiledonar. $\mathrm{Na}$ primeira fase da germinação, entre 24 e 48 horas as sementes já se encontravam intumescidas. Ao intumescer, a testa se desprende, entretanto o tégmen permanece aderido ao albúmen. A raiz primária de coloração esbranquiçada, espessa e lisa, rompeu o tegumento na região basal da semente, próximo ao hilo após quatro dias da semeadura (Figura 3A).

A segunda fase ficou evidenciada pela emissão dos dois cotilédones, 13 dias após a semeadura (Figura 3B). Cotilédones opostos e iguais, $\operatorname{com} 2,7-2,9 \mathrm{~cm}$ de comprimento por $0,8-1,0 \mathrm{~cm}$ de largura, foliáceos, de membranosos a carnosos, glabros, com a porção dorsal verde-amarelada e ventral verde-clara a verde. Hipocótilo reto, cilíndrico, glabro, de coloração verde-clara e com 2,6-4,0 cm de

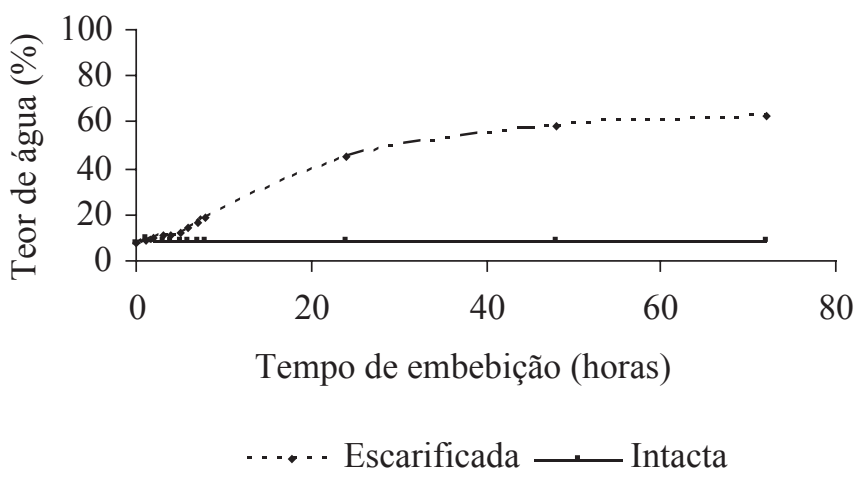

FIGURA 1. Curva de embebição de água das sementes de Dimorphandra wilsonii Rizz. Laboratório de sementes, CCA - UFES. Alegre-ES, 2007. 

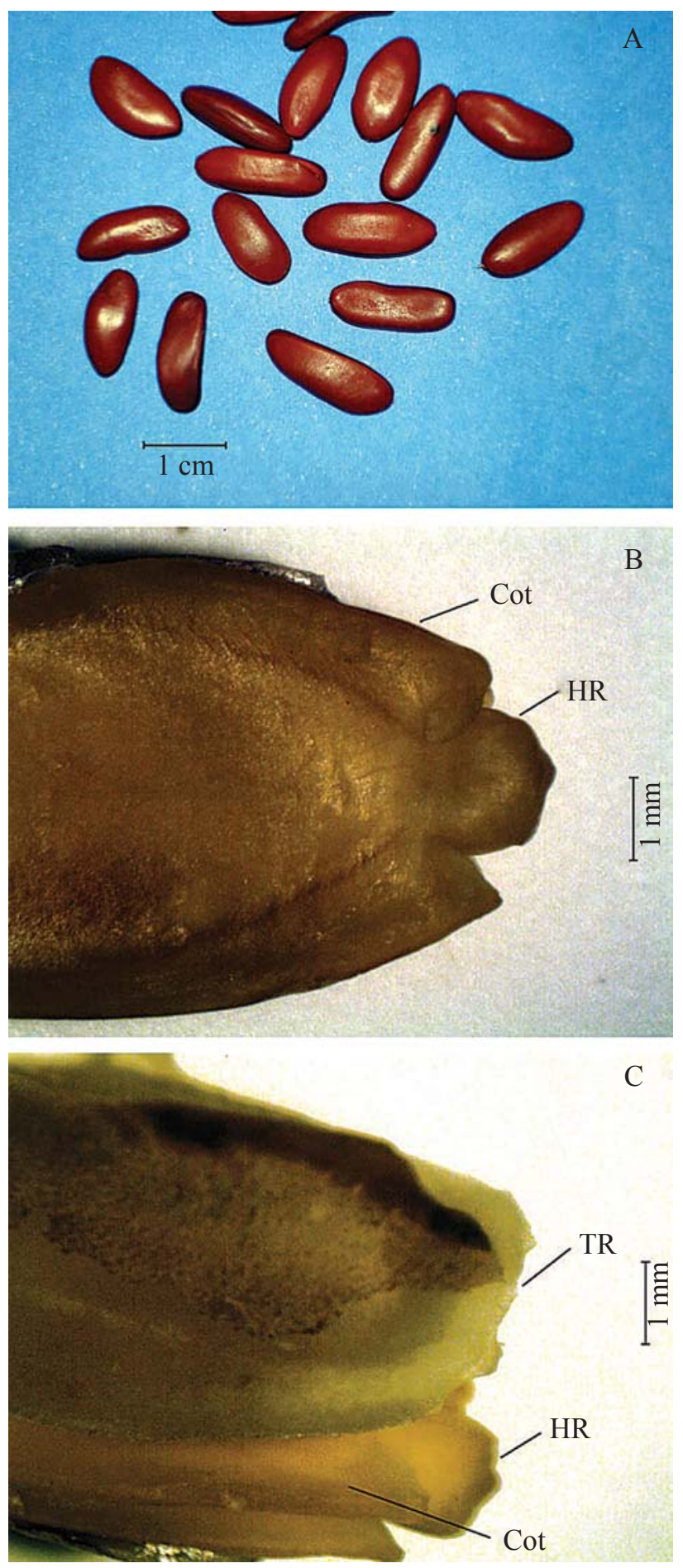

FIGURA 2. Aspectos morfológicos da semente de Dimorphandra wilsonii Rizz.: A - vista externa; B - vista interna sem o albúmen e $\mathbf{C}$ - vista interna mostrando o albúmen. Legenda: $\operatorname{Cot}=$ cotilédone; HR = eixo hipocólito-radícula; TR $=$ tecido de reserva. Laboratório de Sementes, CCA - UFES. Alegre-ES, 2007. comprimento por $0,4 \mathrm{~cm}$ de diâmetro. Colo bem delimitado e muito perceptível pela dilatação que há na região e pela coloração esbranquiçada, diferente em relação ao hipocótilo e a raiz primária. Raiz primária glabra, de coloração brancoparda, pouco sinuosa, de 5,0-6,5cm de comprimento e sem formação de raízes secundárias.

A terceira fase se caracterizou pela emissão dos protófilos, que ocorreu 17 dias após a semeadura (Figura 3C-D). As plântulas apresentavam raiz principal parda, pouco sinuosa, variando de 5,3-11,0cm de comprimento; raízes secundárias evidentes e numerosas próximas ao colo, de coloração branca; hipocótilo verde-esbranquiçado, com 4,0-5,3cm de comprimento e $0,4 \mathrm{~cm}$ de diâmetro, reto, cilíndrico e glabro; dois cotilédones opostos, iguais, persistentes, membranosos a carnosos, sésseis, porção dorsal verde-amarelada e ventral verde, com $2,7-2,9 \mathrm{~cm}$ de comprimento por $0,8-1,0 \mathrm{~cm}$ de largura cada um. Epicótilo de coloração verde-clara, cilíndrico, piloso, com 1,1-2,0cm de comprimento; protófilos com o primeiro par oposto, composto, verde-claro, com 7 a 10 pares de folíolos. Folíolos peninérveos, oblongos, de coloração verde-clara, com ápice obtuso, base oblíqua, bordo inteiro e pulvínulo perceptível; raque de coloração verde-clara, pilosa, com 1,5-1,7cm de comprimento, com pulvino basal e um par de estípulas de coloração verde-clara. No ápice, há uma pequena expansão laminar e pilosa na face ventral, similar à observada em Dimophandra mollis por Ferreira et al. (2001).

\section{CONCLUSÕES}

- SementedeDimorphandrawilsoniiRizzébitegumentada, com tegumento duro e impermeável à água;

- A germinação das sementes é epígea e as plântulas são fanerocotiledonares;

- A estrutura do ápice da plântula de Dimorphandra wilsonii Rizz. apresenta similaridade com a de Dimophandra mollis Benth, sendo ambas pilosas na face ventral;

- A caracterização morfológica das sementes e das plântulas fornecem subsídios que facilitam o reconhecimento desta espécie, principalmente em bancos de sementes.

\section{AGRADECIMENTOS}

Os autores agradecem à Chris Fantoni pelas ilustrações; ao Engenheiro Florestal Fernando Moreira Fernandes e à Bióloga Márcia Bacelar Fonseca, funcionários da Fundação Zôo-Botânica de Belo Horizonte, pela cessão das sementes e apoio ao trabalho e à Engenheira Agrônoma Marilda Torres Capucho, do CCA-UFES, pelo auxílio no trabalho. 

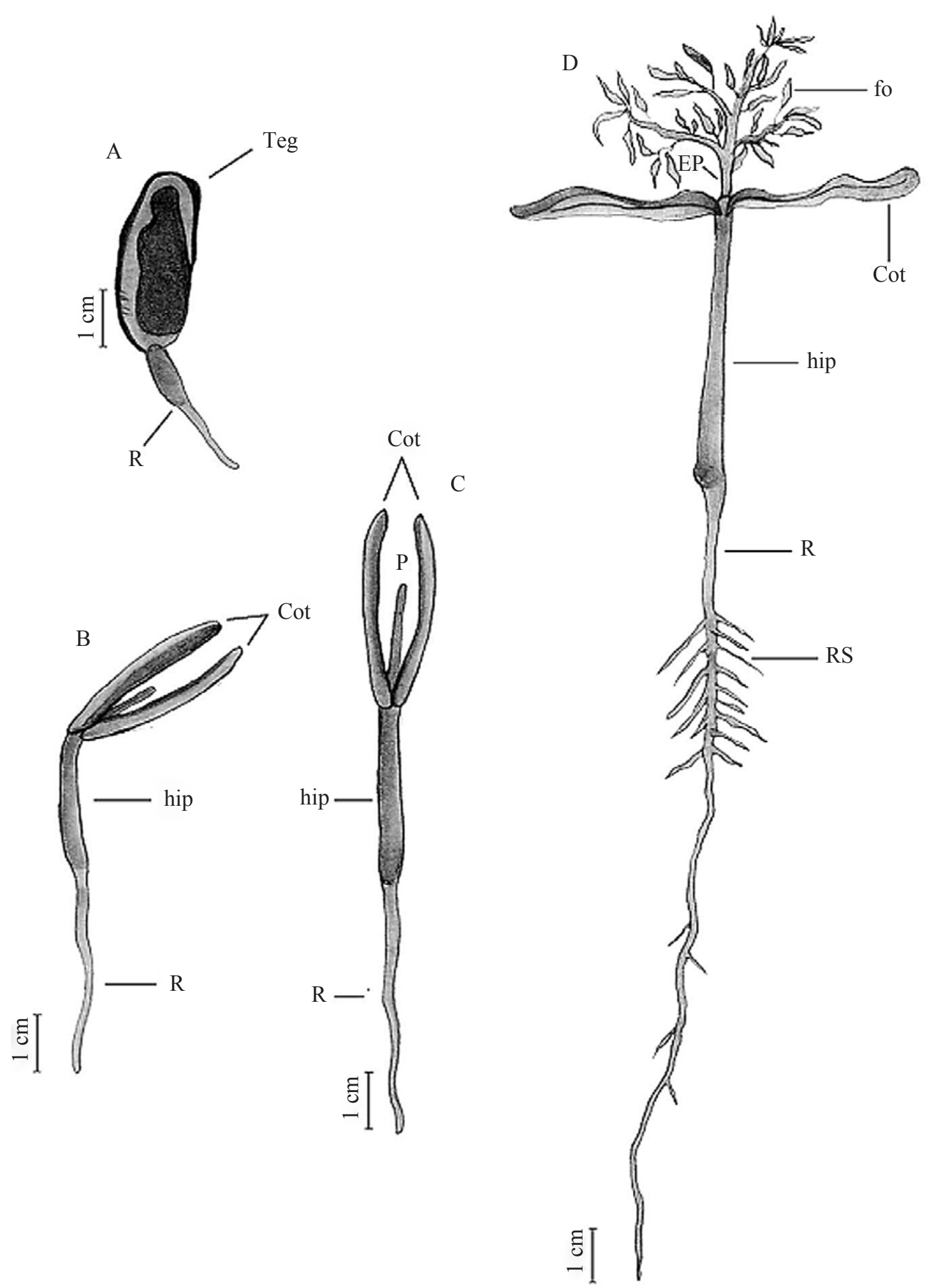

FIGURA 3. Estádios de desenvolvimento de plântulas de Dimorphandra wilsonii Rizz.: A-protrusão da raiz primária; B - emissão de cotilédones; C-D - plântula com protófilos fechados e após abertura. Legenda: Teg =

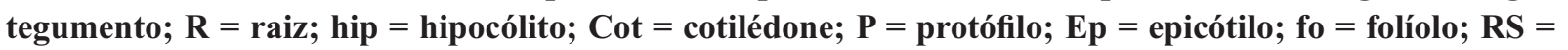
raiz secundária. Laboratório de Sementes, CCA - UFES, Alegre-ES, 2007. 


\section{REFERÊNCIAS}

ABREU, D.C.A.; KUNIYOSHI, Y.S.; NOGUEIRA, A.C.; MEDEIROS, A.C.S. Caracterização morfológica de frutos, sementes e germinação de Allophylus edulis (St.-Hil.) Radlk. Revista Brasileira de Sementes, Brasília, v.27, n.2, p.59-66, 2005a.

ABREU, D.C.A.; KUNIYOSHI, Y.S.; MEDEIROS, A.C.S.; NOGUEIRA, A.C. Caracterização morfológica de frutos e sementes de cataia (Drimys brasiliensis Miers. Winteraceae). Revista Brasileira de Sementes, Brasília, v.27, n.2, p.67-74, 2005 b.

ALVES, T.H.S.; FREITAS, V.L.O.; VIEGAS, F.P.; FERREIRA, R.M.; LEMOS FILHO, J.P. Biometria de frutos e sementes e germinação de duas espécies do gênero Dimorphandra (Leguminosae-Caesalpinioideae). II Dimorphandra wilsonii Rizz., uma espécie vulnerável a extinção. In: CONGRESSO NACIONAL DE BOTÂNICA, 55, 2004, Viçosa. Resumos... Viçosa: SBB, 2004. CD-ROM.

AQÜILA, M.E.A. Tipos de diásporos e suas origens. In: FERREIRA, A.G.; BORGHETTI, F. (orgs.). Germinação: do básico ao aplicado. Porto Alegre: ARTMED, 2004. p.69-92.

BARROSO, G.M.; MORIM, M.P.; PEIXOTO, A.L.; ICHASO, C.L.F. Frutos e sementes: morfologia aplicada à sistemática de dicotiledôneas. Viçosa: UFV, 1999. 443p.

BRASIL. Ministério da Agricultura e Reforma Agrária. Regras para análise de sementes. Brasília: SNDA/DNDV/ CLAV, 1992. 365p.

CRUZ, E.D.; CARVALHO, J.E.U. Biometria de frutos e sementes e germinação de curupixá (Micropholis venulosa Mart. \& Eichler - Sapotaceae). Acta Amazônica, Manaus, v.33, n.3, p.389-398, 2003.

FERNANDES, F.M.; FONSECA, A.G.; KAECHELE, K.; GOULART, M.F.; MARINHO, W.; SOUZA, H.A.V.; QUEIROZ,A.R.;GIORNI,V.;OLIVEIRA,G.;RODRIGUES, M.J.; BACELAR, M.; LOVATO, M.B. Tentando evitar mais uma extinção: o caso do "faveiro de wilson" (Dimorphandra wilsonii Rizzini). In: SAMPAIO, T.; COSTA, M.L.M.N.; JACKSON, P.W. (orgs.). Recuperando o verde para as cidades: a experiência dos jardins botânicos brasileiros. Rio de Janeiro: RBJB/ IPJBRJ/ BGCI, p.87-98, 2007.

FERREIRA, R.A.; BOTELHO, S.A.; DAVIDE, A.C.; MALAVASI, M.M. Caracterização morfológica de fruto, semente, plântula e muda de Dipteryx alata Vogel - baru (Leguminosae-Papilionoideae). Cerne, Lavras, v.4, n.1, p.73-87, 1998.
FERREIRA, R.A.; BOTELHO, S.A.; DAVIDE, A.C.; MALAVASI, M.M. Morfologia de frutos, sementes, plântulas e plantas jovens de Dimorphandra mollis Benth. - faveira (Leguminosae-Caesalpinioideae). Revista Brasileira de Botânica, São Paulo, v.24, n.3, p.303-309, 2001.

GROTH, D.; LIBERAL, O.H.T. Catálogo de identificação de sementes. Campinas: Fundação Cargill, 1988. 183p.

MELO, M.G.G.; MENDONÇA, M.S.; MENDES, A.M.S. Análise morfológica de sementes, germinação e plântulas de jatobá (Hymenaea intermedia Ducke var. adenotricha (Ducke) Lu \& Lang. - Leguminosae-Caesalpinioideae). Acta Amazônica, Manaus, v.34, n.1, p.9-14, 2004.

MENDONÇA, M.P.; LINS, L.V. (orgs.). Lista vermelha das espécies ameaçadas de extinção da flora de Minas Gerais. Belo Horizonte: Fundação Biodiversitas/ Fundação Zôo-Botânica de Belo Horizonte, 2000. 160p.

OLIVEIRA, E.C. Morfologia de plântulas florestais. In: AGUIAR, I.B.; PIÑA-RODRIGUES, F.C.M.; FIGLIOLIA, M.B. (coord.). Sementes florestais tropicais. Brasília: ABRATES, 1993. p.175-214.

PIÑA-RODRIGUES, F.C.M; COSTA, L.G.S.; REIS, A. Estratégias de estabelecimento de espécies arbóreas e o manejo de florestas tropicais. In: CONGRESSO FLORESTAL BRASILEIRO, 6, 1990, Campos do Jordão. Anais... São Paulo: SBS, 1990. p.676-684.

SILVA, M.F. Dimorphandra (Caesalpiniaceae) In: Flora Neotropica. New York: The New York Botanical Garden. Monograph 44. v.2, 1986. 128p.

SILVA, L.M.M.; MATOS, V.P. Morfologia da semente e da germinação de Erythrina velutina Willd. Revista Árvore, Viçosa, v.15, n.2, p.137-143, 1991.

SILVA, G.M.C.; SILVA, H.; ALMEIDA, M.V.A.; CAVALCANTI, M.L.F.; MARTINS, P.L. Morfologia do fruto, semente e plântula de mororó (ou pata-de-vaca) Bauhinia forficata Linn. Revista de Biologia e Ciências da Terra, Campina Grande, v.3, n.2, 2003. Disponível em: $<$ http://www.uepb.edu.br/eduep/rbct/sumarios/pdf/mororo. pdf $>$. Acesso em: 10 jun. 2006.

SOUZA, L.A. Morfologia e anatomia vegetal: célula, tecidos, órgãos e plântula. Ponta Grossa: UEPG, 2003. 259 p.

VIDAL, W.N.; VIDAL, M.R.R. Botânica: organografia. 4.ed. Viçosa: UFV, 2003. 124p. 